\title{
WHO/MOHFW-Guidelines to practice prosthodontics and implant procedures during COVID-19 pandemic
}

\author{
Sukhitha Ramesh ${ }^{1}$, Leoney A ${ }^{2, *}$, Seyed Asharaf Ali $^{2}$ \\ ${ }^{1}$ CRRI, Government Dental College, Chidambaram, Cuddalore, Tamilnadu, India. \\ ${ }^{2}$ Professor, Department of Prosthodontics, Government Dental College, Chidambaram, Cuddalore, Tamilnadu, India.
}

\author{
Article History \\ Received $4^{\text {th }}$ June 2021 \\ Received revised \\ $23^{\text {rd }}$ August 2021 \\ Accepted $10^{\text {th }}$ September2021 \\ Available online \\ $6^{\text {th }}$ February 2022

\section{*Correspondence \\ Leoney A \\ Professor \\ Department of Prosthodontics \\ Government Dental College \\ Chidambaram, Cuddalore, Tamilnadu, India. \\ E-mail: antony.leoney@gmail.com \\ Dol: $h$ ttp://dx.doi.org/10.37983/IJDM.2022.4104}

\section{Introduction}

SARS-CoV-2, the virus that causes COVID-19, is spread between people in close contact with one another (within 6 feet). Transmission is mainly by respiratory droplets produced when an infected person coughs, sneezes, or talks. Oral fluids and aerosols exhibit a long incubation period of the virus and have proven to be high-risk causatives for the transmission of the virus. Dental healthcare has faced several clinical, psychological and financial repercussions due to the risk involved. The significant reasons for fear and dilemma in the minds of practitioners is due to asymptomatic carriers [1,2]. The use of rotary dental and surgical devices in dentistry, such as airotors, ultrasonic scalers and air-water syringes, produce a visible spray including water, saliva, blood, microorganisms (bacteria, virus, etc.) and other debris. Mucous membranes of the mouth and nose are protected from droplet spatter by a surgical mask, but they do not provide complete protection against the inhalation of infectious agents $[3,4]$. As a result, during pandemics, modifications to the prosthodontic and implant procedures, as well as pertinent guidelines, are critical $[1,5,6]$. World health organisation (WHO) and Ministry of Health and Family Welfare (MOHFW) Government of India have given recommendations for the practice of general dentistry and prosthodontics in Covid times to facilitate the governments, institutions and clinics to carry on service effectively and safely.

\section{General Considerations $[1,7]$}

\subsection{Recommendations for clinic designing set-up}

The clinical setup needs separate areas for sterilization rooms. The feasibility depends upon basic infrastructure, the total number of areas available, the number of health care workers, and the number of patients reporting per day. These protocols applied to both private and government clinics.

\subsubsection{Zone A: Reception and waiting area [1,2]}

The two procedures to be carried out in this zone include, a) Temperature recording using a digital thermometer, b) Arterial oxygen saturation monitoring using a pulse oximeter.

Facilities like sensor taps and contactless sanitizer dispensers are mandatory. A triple-layer face mask, disposable shoe covers, head cap and gloves should be provided. A glass barrier can be installed between the patient and the staff to prevent the transmission of droplets. The patient should fill out the informed consent in the language of his or her preference. The patient should be asked to remove accessories like jewellery, watch etc., and thoroughly sanitize their hands. Physical distancing and digital payments are a few other recommendations.

\subsubsection{Zone B: Screening Area [1,2]}

Sterilized instruments are used for initial screening and diagnosis. During the early onset of the disease, a maximum viral load $\left(2.35 \times 10^{9}\right.$ copies per ml of sputum) is present in the upper respiratory tract. The oral preparation of Povidone-iodine for 15 seconds is used as a preprocedural mouth rinse, which completely deactivates the virus. Other chemical preparations that disrupt the viral lipid barrier 
include ethanol, chlorhexidine, cetyl pyridinium chloride, and hydrogen peroxide. OPG and CBCT are favoured over intraoral radiographs when taking radiographs to avoid salivary contamination. Digital radiographs are recommended.

\subsubsection{Zone C: Non-aerosol generating area [4]}

Airoter handpieces and ultrasonic scalers uses minimized. Hand instruments such as spoon excavators and chemical based caries removal agents are preferred. Personal protective equipment (PPE) is effective in preventing the spread of infection. Protocols for donning and doffing should be followed (Tables 1 and 2). Digital workflow is recommended. Double-layer bags are used for COVID waste disposal. Yellow bins are used for PPE disposal and biomedical waste management should be done properly (Table 3).

\subsubsection{Zone D: Aerosol generating area [2]}

Aerosols are most commonly generated during the use of high-speed handpieces and even after the completion of the procedure remain suspended in the air for 30 minutes and can reach up to 2 feet from the dental chair. Minimize the use of ceiling fans and air conditioners. High volume evacuators and high-efficiency filters (HEPA Filters) are used to filter the contaminated room air. In order to avoid direct contact with the splatter 8'o clock chair position should be avoided. Rubber dams, slow speed anti retraction handpiece and high-volume suction are preferred over chair side suction. $70 \%$ of airborne particles are minimized by using a rubber dam during procedures. $99.97 \%$ of the dust and other airborne particles are filtered using HEPA filters. Usage of an appropriate mask is mandatory. The Dos and DONTs of wearing the mask are tabulated in Table: 4 .

\section{Teledentistry/Tele Consultation/ Videoconferencing [5,7]}

They are indicated during pandemic times in situations of lockdown for a remote dental screening, making the diagnosis, providing consultation and postponing treatment plans and prescribing medicines.

\section{Table 1. Donning PPE: Step by step procedure $[5,7]$}

\begin{tabular}{ll}
\hline Step 1 & Put on scrubs \\
\hline Step 2 & Put on shoe covers/trauma boots as indicated \\
\hline Step 3 & Perform hand hygiene \\
\hline Step 4 & Put on N95 \\
\hline Step 5 & Put on inner cap \\
\hline Step 6 & Put on surgical mask \\
\hline Step 7 & Put on goggles \\
\hline Step 8 & Put on outer cap \\
\hline Step 9 & Again, perform hand hygiene \\
\hline Step 10 & Put on gown \\
\hline Step 11 & Put on surgical gloves \\
\hline Step 12 & Put on double surgical gloves \\
\hline
\end{tabular}

Table 2. Doffing PPE: Step by step procedure $[5,7]$

\begin{tabular}{ll}
\hline Step 1 & Remove gown and gloves, blending forward. \\
\hline Step 2 & $\begin{array}{l}\text { Have gloves removed as one unit with gown. Do not } \\
\text { touch outside of gloves with bare hands. }\end{array}$ \\
\hline Step 3 & Perform hand hygiene. \\
\hline Step 4 & Put on exam gloves. \\
\hline Step 5 & Remove outer cap, bending forward. \\
\hline Step 6 & Remove shoe covers/trauma boots. \\
\hline Step 7 & Remove gloves. \\
\hline Step 8 & Perform hand hygiene. \\
\hline Step 9 & Put on new gloves. \\
\hline Step 10 & $\begin{array}{l}\text { Bending forward, remove goggles, surgical mask and } \\
\text { cap. }\end{array}$ \\
\hline Step 11 & Remove N95. \\
\hline Step 12 & Perform hand hygiene and put on new mask and cap.
\end{tabular}

Table 3. Color coding for segregation of biomedical waste $(1998)[2,8]$

\begin{tabular}{lll}
\hline COLOR & WASTE & TREATMENT \\
\hline Yellow & $\begin{array}{l}\text { Human and animal } \\
\text { anatomical waste/ } \\
\text { microbiology waste } \\
\text { and soiled cotton/ } \\
\text { dressings/ linen/ } \\
\text { bedding etc. }\end{array}$ & Incineration/deep burial \\
& $\begin{array}{l}\text { Tubing, catheters, } \\
\text { Intravenous sets }\end{array}$ & $\begin{array}{l}\text { Autoclave/microwaving/ } \\
\text { chemical treatment }\end{array}$ \\
\hline Red & $\begin{array}{l}\text { Waste sharps } \\
\text { (needles, syringes, } \\
\text { scalpels, blades etc.) }\end{array}$ & $\begin{array}{l}\text { Autoclave } \\
\text { /microwaving/chemical } \\
\text { treatment /destruction } \\
\text { /shredding }\end{array}$ \\
\hline Black & $\begin{array}{l}\text { Discarded medicine } \\
\text { /cytotoxic drugs, } \\
\text { incineration ash, } \\
\text { chemical waste. }\end{array}$ & Disposable in land fields \\
& & \\
\hline
\end{tabular}

\section{Disinfection protocols for dental clinics and laboratories [1,6,7] (Table: 5)}

The clinics and laboratory should be disinfected. Cross infection and transmission should be prevented. The recommended solutions for surface disinfection are sodium hypochlorite solution, ethanol and vaporizer hydrogen. Terminal disinfection for dental clinic and laboratories: UV-C (germicidal effect, wavelength $=200-280 \mathrm{~nm}$ ). Biomedical waste management should be done in an appropriate manner as described in Table 3.

\subsection{Fumigation versus fogging $[1,4]$}

The two methods which are used for disinfection of clinics and laboratories are fumigation and fogging. Fumigation formaldehyde solution mixed with potassium permanganate in a fixed proportion is used in fumigation, which is very effective in killing bacteria, fungus and their spores. Fumigation is effective at above the temperature of $20^{\circ} \mathrm{C}$ and relative humidity of 65\%. Step:1 Preparation: Thoroughly clean windows, doors, floors, walls, surgical table, dental 
chair, and all washable equipment with soap water. Close windows and ventilators tightly in order to avoid the leak of fumes. Switch off all lights, AC and other electrical and electronic al items. Calculate the required amount of formaldehyde for available space. Step 2: Precaution: formaldehyde is irritant to the eye and nose, and it has also been recognised as a potential Carcinogen. So, the Fumigating person must be provided with personal protective equipment. Paste a warning notice on the front of the door indicating fumigation is in progress. Step 3: Fumigation: For every 1000 cubic feet, $500 \mathrm{ml}$ of formaldehyde (40\%solution) is added in $1000 \mathrm{ml}$ of distilled water in an electric boiler. Switch on the boiler, leave the room and seal the door. After 45 minutes, switch off the boiler without entering the room. Step 4: Neutralisation: the toxicity of formaldehyde vapours should be neutralised by ammonia solution.

Fogging: The mixture of hydrogen peroxide and silver ion solution or third Generation quaternary ammonium compounds are used in fogging. They are effective against viruses and other biological agents in the air and on surfaces. Forty-five minutes are required for these nontouch surface disinfections. Circulation of clean and natural air is recommended for these procedures.

\section{Prosthodontic considerations during COVID- 19 era}

\subsection{MOHFW recommendations [1, 5-7]}

All elective procedures are indefinitely postponed. Based on the risk profile the districts in India are classified as green, red and orange zones. Green Zone is zero confirmed cases or no confirmed cases for the past 21 days. Red zones or hotspots are districts with increased active cases, a faster doubling rate. Orange zone is districts, which fall between the green and red zones. Emergency procedures alone are managed in red zones. In orange and green zone surgery procedures can be done. All routine and elective procedures should be deferred for a later review until new policy /guidelines are issued. Due to the high risk associated with the examination of the oral cavity screening program should be deferred until new policy/guidelines are issued.

\subsection{List of emergency and urgent dental procedures to be carried out}

- Mobile/Faulty Prosthesis.

- Fixed faulty prosthesis.

- Infections around prosthesis.

- Periimplantitis.

- Sensitive/caries of abutment underneath fixed prosthesis.

- Fabrication of surgical and interim obturators.

- Dislodged prosthesis needing recementation.

\subsection{Recommendations for removable prosthodontics [6-8]}

Complete and partial dentures fabrication can be done in removable prosthodontics. Increasing covid - 19 mortality rate and co-morbidities are risk factors for geriatric patients. For geriatric patients thorough medical case history is a must before starting any procedure involving removable prosthodontics.

\section{Table 4. Do's and Don'ts of wearing a medical mask} safely [9]

\section{Do's.} Don'ts

Wash your hands before Do not wear a loose mask touching the mask

Inspect the mask for tears or Do not touch the front of the holes.

Find the top side, where the metal piece or stiff edge is. mask

Ensure the colored side faces Do not wear the mask only outwards. over the mouth or nose

Place the metal piece or stiff Do not remove the mask to edge over your nose talk to someone or do other things that would require touching the mask

Cover your mouth, nose, and Do not leave your used mask chin. within the reach of others

Adjust the mask to your face without leaving gaps on sides

Avoid touching the mask.

Remove the mask from

behind the ears or head.

Keep the mask away from you and surfaces while removing it.

Discard the mask immedia-

tely after use preferably into

a closed bin.

Wash your hands after

discarding the mask

Table 5. Disinfection of various materials and equipment in a dental setting $[1,5,6]$

\begin{tabular}{|c|c|}
\hline Materials & $\begin{array}{l}\text { Method and material of } \\
\text { disinfection }\end{array}$ \\
\hline Alginate and polyether & $\begin{array}{l}0.5-1 \% \text { Sodium hypochlorite } \\
\text { (1:10 dilution) or } 1: 213 \\
\text { iodophors (spray) }\end{array}$ \\
\hline $\begin{array}{l}\text { Zinc Oxide Eugenol } \\
\text { impression paste }\end{array}$ & $\begin{array}{l}2 \% \text { Glutaraldehyde or } 1: 213 \\
\text { iodophors: immersion for } 10 \\
\text { minutes. }\end{array}$ \\
\hline Impression compound & $\begin{array}{l}\text { Sodium hypochlorite } \quad(1: 10 \\
\text { dilution) (immersion) }\end{array}$ \\
\hline Elastomers & $2 \%$ Glutaraldehyde or cidex \\
\hline Wax rims & Iodophors disinfection sprays \\
\hline Acrylic appliance & $\begin{array}{l}\text { Povidone-iodine } / 1 \% \\
\text { hypochlorite, store in mouth } \\
\text { wash before use }\end{array}$ \\
\hline Fixed prosthesis & $\begin{array}{l}\text { immersion in cidex, or } 1 \% \\
\text { Sodium hypochlorite }\end{array}$ \\
\hline Gypsum casts & $\begin{array}{l}\text { Microwave irradiation for } 5 \mathrm{~min} \\
\text { at } 100 \mathrm{~W}\end{array}$ \\
\hline Tips of intra oral scanners & $\begin{array}{l}\text { Rubbing with alcohol-based } \\
\text { disinfectant }\end{array}$ \\
\hline
\end{tabular}




\subsubsection{Chairside protocol}

a. Advise topical analgesic and antiseptic gels for ulceration and mucosal erosion through teleconsultation.

b. The patient should be asked to discontinue the prosthesis for some time in case of any irritation.

c. Before repairing the fractured prosthesis, first, disinfect it thoroughly.

d. A low-speed micro motor should be used for denture adjustment.

e. Snap impression should be done followed by disinfection using glutaraldehyde.

f. Modification of final impression for complete dentures with a single step border moulding technique.

g. Virtual face bow records and jaw relation records can be made.

h. Digital workflow for a precise prosthesis can be adopted.

i. For interim or cast partial denture prosthesis fabrication, CAD/CAM systems, which are precise and require lesser chair side adjustments can be used.

\subsubsection{Laboratory protocol for Removable Prosthodontics}

Record bases and wax rims should be adjusted before inserting them into the patient mouth. To adjust the occlusion, dentures should be remounted, and processing errors should be minimized. This will reduce the chairside time.

\subsection{Recommendations for fixed prosthodontics $[9,10]$}

In fixed prosthodontics crowns and bridges, inlays, onlays, smile designing, veneers, full mouth rehabilitation, post and cores are fabricated. Strict precautions and disinfection protocols are mandatory because these are elective and aerosol-generating procedures. Safe alternative methods such as digital impressions using intraoral scanners could be used. Digital workflow is preferred over conventional workflow.

\subsubsection{Chairside protocol}

During tooth preparation, the use of a rubber dam and high vacuum suction are recommended. Here supra gingiva margins are recommended. Undercuts, under reduction, should be avoided. A digital spectrophotometer is used for shade selection and consent of the patient should be taken. Crown removers for the removal of the fractured and faulty prosthesis. Frequent rinsing and spitting should be minimized. In 3-way syringes, air pressure should be reduced. $11-12$ o'clock is recommended chair position to reduce contamination.

\subsubsection{Laboratory protocol}

Cross-contamination between clinic and lab is most commonly due to impressions. Impressions should be disinfected with sodium hypochlorite $1 \%$ for 10 mins and stored in disposable pouches. Computed aided designed and milled restorations should be preferred to avoid contamination. Conventional casting should be avoided during the pandemic time. The prosthesis should be immersed in disinfectant before sending it back to the clinic and before inserting it into the patient mouth.

\subsection{Recommendations for implant surgery and prosthesis [6,7]}

\subsubsection{Chairside protocol}

Slow Speed drilling with sharp drills is preferable. Intermittent external irrigation along with high volume suction should be done. The use of ultrasonic devices and piezoelectric surgery should be minimized, whereas the use of osteotomes should be encouraged in order to minimize aerosol formation. Avoid complex full mouth procedures. The digital impression is an alternative to conventional impression making.

\subsubsection{Laboratory protocol}

Implant impressions and components need to be carefully disinfected/autoclaved before reusing them. Careful impressions making using resin jig and precise pouring of the impressions are a must in order to prevent the repetition of any chairside step.

\section{Intraoral and extraoral maxillofacial prosthesis}

Fabrication of surgical and interim obturators must be done at this time to restore the function of patients with intraoral defects. Facial defects may act as esthetic urgencies. Additionally, psychological counselling and motivation for the maintenance of the prosthesis can be done through Tele dentistry.

\section{Conclusion}

In this COVID-19 pandemic, the mental health of the dentist and the dental health of the patient are in question. Care should be taken at every step namely, a collection of the dental impression, pouring of the models, designing and fabrication of prosthesis, finishing and polishing. Disinfection protocols should be followed to prevent the further spread of infection.

Conflicts of interest: Authors declared no conflicts of interest.

\section{Financial support: None}

\section{References}

1. Ministry of Health and Family Welfare, Government of India. Guidelines for Dental professionals in Covid - 19 pandemic situation. New Delhi, India: Ministryof Health and Family Welfare, Government of India;2019 http://www.mohfw.gov.in/pdf/Dental Advisory. Pdf.

2. Salvi SS. In this pandemic and panic of COVID-19 what should doctors know about masks and respirators? http://apiindia.org/wpcontent/up-oads/pdf/coronavirus/review-article-onmask.pdf International Journal of Dental Materials 2022;4(1):17-21 @ 2022 by the IJDM 
3. Lu H, Stratton CW, Tang YW. Outbreak of pneumonia of unknown etiology in Wuhan, China: the mystery and the miracle. J Med Virol. 2020;92: 401-2. https://doi.org/10.1002/jmv.25678

4. Balkhair AA. COVID-19 pandemic. A new chapter in the history of infectious diseases. Oman Med J. 2020;35:e123e124.

https://doi.org/10.5001/omj.2020.41

5. Abramovitz I, Palmon A, Levy D, et al. Dental care during the coronavirus disease 2019 (COVID-19) outbreak: operatory considerations and clinical aspects. Quintessence Int 2020;51:418-429.

https://doi.org/10.1161/STROKEAHA.120.029701

6. World Health Organization. Rational Use of Personal Protective Equipment for Coronavirus Disease (Covid 19)and Considerations during severe shortages:Interim guidance. 2020;2020. Available from:

http://apps.who.int/iris/handle/10665/331695,_Accessed $25^{\text {th }}$ April 2020.

7. Villani FA, Aiuto R, Paglia L, Re D. COVID-19 and dentistry: prevention in dentalpractice, a literature review. Int J Environ Res Publ Health. 2020;17:4609. https://doi.org/10.3390/ijerph17124609

8. Kalidindi SS, Ravi Kumar C, Sujesh M, Lukka P. Management of dental office during COVID-19 Pandemic. Int J Dent Mater. 2021;3(1):24-32. https://doi.org/10.37983/IJDM.2021.3104

9. Jamal M, Shah M, Almarzooqi SH, Aber H, Khawaja S, El Abed R, Alkhatib Z, Samaranayake LP. Overview of transnational recommendations for COVID-19 transmission control in dental care settings. Oral Diseases. 2021;27:655-64. https://doi.org/10.1111/odi.13431.

10. Advice on the Use of Masks in the Context of COVID-19: Interim Guidance. World Health Organization.

How to cite this article: Ramesh S, Leoney A, Ali SA. WHO/MOHFW- Guidelines to practice prosthodontics and implant procedures during COVID-19 pandemic. Int J Dent Mater. 2022; 4(1): 17-21.

DoI: http://dx.doi.org/10.37983/IJDM.2022.4104 